\title{
Study on the causes of secondary cracks of the eave wall mural of Daxiong Hall at Fengguo Temple in Yixian, Liaoning, China
}

\author{
Cheng Liu', Yuan He ${ }^{1 *} \mathbb{C}$, Qian Li ${ }^{2}$ and Fei Wang ${ }^{3}$
}

\begin{abstract}
Built in Kaitai 9 years after the beginning of the Liao Dynasty (1020 A.D.), the Daxiong Hall of Fengguo Temple (Yixian County, Liaoning Province) is one of China's largest existing ancient single-eave wooden architecture structures. In 2012, it was listed on the "Preliminary List of World Cultural Heritage in China." Preserved Buddhist murals depicting the Yuan Dynasty cover approximately $470 \mathrm{~m}^{2}$ of the hall's four walls. Since the in-situ reinforcement and protection of the mural, conducted in the 1980s in cooperation with the maintenance and restoration project of the main hall, seriously developed cracks — known as secondary cracks— have become a primary factor affecting the mural's structural stability. In this study, we conducted a comprehensive investigation using a full-frame digital camera, an industrial endoscope, an infrared thermal imager, an online environmental monitoring system, and a three-dimensional laser scanner. Our results, and other relevant materials, allowed us to deepen our understanding of the existing structural features, the nature of the cracks, the deformation conditions, and the environmental characteristics of the mural. Moreover, we provide a further discussion on the macroscopic formation process of the secondary cracks.
\end{abstract}

Keywords: Fengguo Temple, Mural, Eave wall structure, Secondary disease, Crack

\section{Introduction}

One of ancient China's most prominent type of murals was the architectural variety. They appear on the walls of ancient buildings and are an organic part of the building's architectural structure. The rationality of the structure-especially relating to the walls-has an important influence on the stability of the mural body. Indeed, what is known as "crack disease" is a common manifestation of a mural's structural instability, and its causes mostly relate to (among others) the influence of micro-vibration [1], the deformation and settlement of building enclosing structures [2, 3], and the extrusion caused by the expansion of inner wood columns [4]. The existing cracks on the eave wall mural of Fengguo Temple's Daxiong Hall mostly appeared after the in-situ reinforcement and

\footnotetext{
*Correspondence: heyuan4053@163.com

${ }^{1}$ School of Cultural Heritage, Northwest University, Xi'an, China

Full list of author information is available at the end of the article
}

protection project in the 1980s. These types of cracksoften the result of secondary disease caused by protection and treatment measures-differ from more general ones. This problem received increasing levels of academic attention in recent years. Much of the research has focused on the failure mechanisms of protective materials [5], their direct impact on the mural body [6,7] as well as removal methods [8,9]. Moreover, past research has mainly focused on detached murals, with less attention having been paid to the systematic causes of complex secondary diseases and architectural murals preserved insitu. Furthermore, studies on the mechanisms of in-situ preserved mural diseases from the perspective of architectural pathology have also been conducted $[10,11]$, but they often focus on the corresponding relations between the coordination of multiple factors and the manifestations of multiple diseases, meaning that the specific formation process of a single disease has not been discussed in sufficient depth.

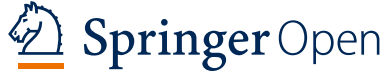

(c) The Author(s) 2021. Open Access This article is licensed under a Creative Commons Attribution 4.0 International License, which permits use, sharing, adaptation, distribution and reproduction in any medium or format, as long as you give appropriate credit to the original author(s) and the source, provide a link to the Creative Commons licence, and indicate if changes were made. The images or other third party material in this article are included in the article's Creative Commons licence, unless indicated otherwise in a credit line to the material. If material is not included in the article's Creative Commons licence and your intended use is not permitted by statutory regulation or exceeds the permitted use, you will need to obtain permission directly from the copyright holder. To view a copy of this licence, visit http://creativecommons.org/licenses/by/4.0/. The Creative Commons Public Domain Dedication waiver (http://creativeco mmons.org/publicdomain/zero/1.0/) applies to the data made available in this article, unless otherwise stated in a credit line to the data. 
The specialized study of secondary cracks is a vital part of the protection research project of Fengguo Temple's mural. While previous research [12] has discussed the relation between the deterioration of additional materials and the causes of secondary cracks, a lack of research techniques has limited the (admittedly limited) conclusions drawn, and a complete evidence chain has yet to be formed. Accordingly, this paper makes a systematic analysis of the comprehensive investigation materials, and interprets the regularities of distribution of stress release as well as the coupling relations between the environment and the mural body, thereby constructing a formation path model of the secondary cracks and providing a case reference for future studies.

\section{Investigation content and methods Investigation content}

The investigation content of this study can be divided into five parts:

(1) The basic information of the study object, including the mural's theme, size, and location;

(2) The nature of the secondary cracks, including the developmental direction, the layer reached, the connectivity, etc. They are concrete manifestations of the problem studied. Secondary cracks refer to those which have been generated since the mural's in-situ reinforcement and protection in the 1980s;

(3) The existing structural features of the mural, including the basic structure of painting and eave wall structure, both of which relate to the internal causes of the disease;

(4) Characteristics of the mural's environment (both macro and micro), including the air fluidity, the change of temperature and humidity, and the heat conduction. They are related to the external causes of the disease;

(5) The deformation of the mural surface, that is, the displacement of the points on the mural's surface over time. Such displacement is typically caused by the joint action of internal and external factors, and reflects the distribution of internal stress.

\section{Investigation methods}

We collected the original materials related to the abovementioned investigation content either on site or by consulting historical documents. We processed certain materials using software. These materials were then analyzed and integrated in series, before finally recreating the macro formation process of the secondary cracks. The devices (see Table 1) and methods used were all nonharmful to cultural relics.

\section{Investigation of the mural's basic information}

We identified the mural's theme, content, and distribution through on-site observation. We directly measured the length of each section of the eave wall with a laser rangefinder, and calculated the height with some measured values using the geometric method.

\section{Investigation of the secondary crack's nature}

Our plan was to first mark all of the mural's existing cracks, and then afterwards identify which had been generated since the in-situ reinforcement and protection. Once done, we could begin our analysis of these secondary cracks.

The marking of the cracks seemed somewhat similar to the drawing of disease maps in heritage conservation works. We used the multi-segment line tool of AutoCAD software to manually trace the trend of the cracks on the background photos of the mural, which allowed us to then export vector diagrams. The definition of the photos determined the accuracy of the cracks' marking. Therefore, we photographed the mural in blocks from a short distance with a full-frame digital camera, and then stitched these individual photographs together using Photoshop to create six integrated images: the mural on the east wall, the west wall, the west section of the north wall, the east section of the north wall, the west section of the south wall, and the east section of the south wall.

We based the identification of the secondary cracks on comparisons between previous and recent photographs, as well as on-site observation. Through the former method, we were able to exclude those cracks that had existed before the 1980s initially. We then individually observed each crack at close range with the help of a scissor-type aerial working platform, thereby enabling us to exclude shallow cracks resulting from normal moisture changes. Furthermore, the cracks at filled missing parts and those which reached to added support layers were directly identified as secondary cracks by the intrusion relation method in archaeology. Any crack whose nature we were unable to determine was considered as being original (i.e., pre-1980s).

\section{Investigation of the mural's existing structures}

The structure of the mural has remained relatively unchanged since the reinforcement and protection work in the 1980s, meaning that the engineering report [13] at that time is the main reference for understanding its existing structures. We obtained additional, and more detailed, information about the structure through on-site investigation.

The seriously developed longitudinal secondary cracks at the eave column positions provided entrances from 


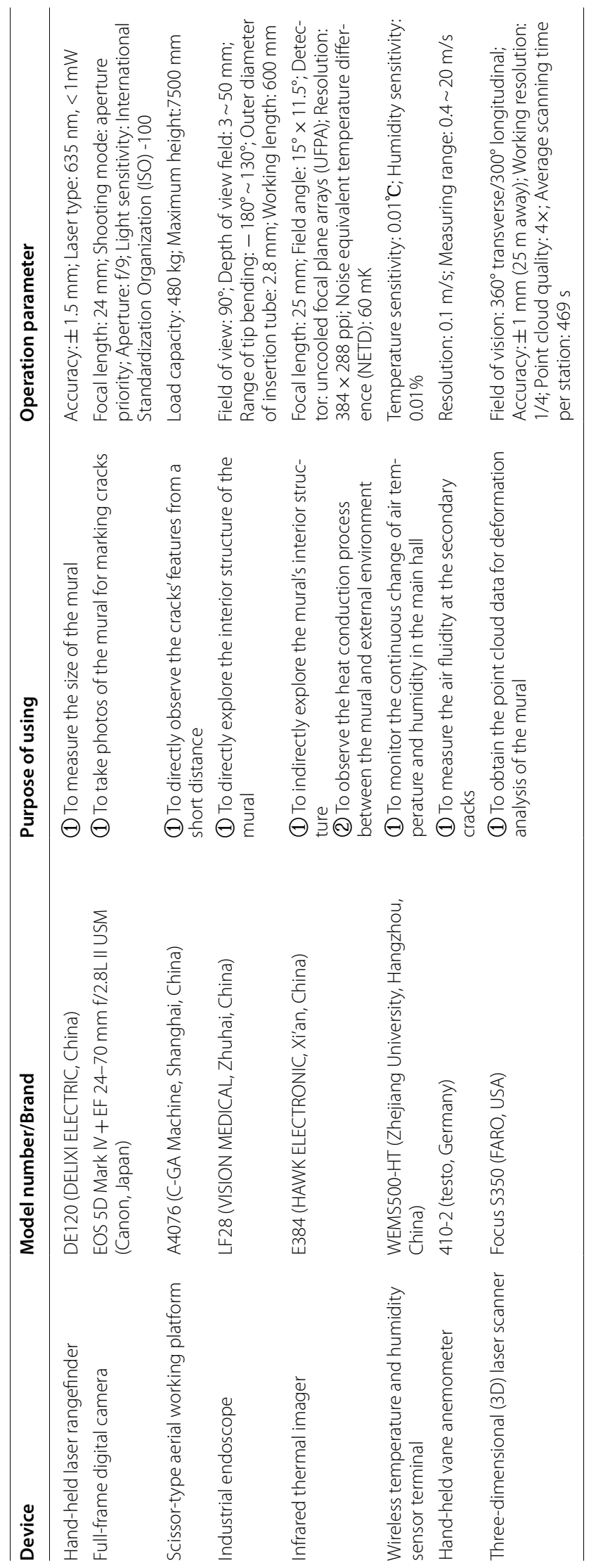


which to directly explore the mural's interior structure. The images behind the additional support layer were easily obtained with an industrial endoscope.

The eave wall is the medium of heat exchange between the building and atmospheric environment, and its interior structural features are reflected in the infrared thermal images of its surface due to differences in the heat conduction's path. Therefore, when the external temperature changes dramatically, using an infrared thermal imager to observe the mural's surface can achieve a partial degree of "see through" effect.

\section{Investigation of the mural's environment}

The macro-environment characteristics can be understood by consulting the climatic and meteorological materials of Yixian County (where Fengguo Temple is located). We mostly examined the near-surface atmospheric temperature and relative humidity monitored at Yixian through a national meteorological observation station $\left(41^{\circ} 31^{\prime} \mathrm{N}, 121^{\circ} 14^{\prime} \mathrm{E}, 68.5 \mathrm{~m}\right)$ [14]. The monitoring was automatically conducted by sensors.

Micro-environment data were obtained through onsite monitoring. We placed a wireless temperature and humidity sensor terminal (developed by Zhejiang University) at the root of the north wall (at the junction of N6 and N7). Real-time data was automatically collected and then uploaded to the local area network (LAN) through a gateway device (an hour as a cycle), meaning that we were able to continuously monitor the air temperature and relative humidity in the main hall.

We also placed a handheld vane anemometer toward longitudinal secondary cracks to measure the area's air fluidity. Again, we employed the infrared thermal imager to take infrared photos of the same position on the mural at different times of the day. We could thus specifically analyze the heat conduction process between the external environment and the mural body.

\section{Investigation of the deformation on the mural's surface}

We selected the mural in the northwest corner of the main hall (sections N1, N2 and W4, W5) as the investigation object, and we collected point cloud data of its surface four times using a three-dimensional (3D) laser scanner. We set the results of the first scan as the benchmark, with the remaining three scans being used for a comparison with which to conduct deviation analysis. We thus obtained the deformation information on the surface of the mural. In order to ensure the operability and accuracy of the deviation analysis, three fixed target balls were set on the hard ground in front of the mural during the investigation to act as "null displacement" reference objects, and their point cloud data were also collected together with the mural's. Accordingly, the absolute displacement was transformed into a relative displacement, which facilitated the target alignment processing in the subsequent analysis.

We used Geomagic Control 3D detection software for the deviation analysis. This software can visually reflect the deviation from two scans of the same object through a chromatogram, where different color blocks represent the degree and direction of the deformation at different locations. Further to this, the deviation values calculated by the software can be used to further discuss the mural's overall deformation.

\section{Results and discussion Investigation results The mural's basic information}

Daxiong Hall is a single-eave, hip-roofed, south-facing building (Fig. 1). It is nine units wide and five units deep ("unit" here refers to the section between two adjacent eave columns). After the maintenance and restoration project, the building's enclosing structure consists of partition doors and eave walls - the former includes seven units in the middle of the front facade and a central unit in the back facade, and the latter includes the remaining units. The mural depicting the Yuan Dynasty was painted on the entire inner surface of the eave wall, and the content of each unit is independent. There are five Buddhas painted on the each of the east and west walls (E1-5, W1-5), four Bodhisattvas each on the east and west sections of the north wall (N1-8), and an 11-faced Avalokitesvara painted on each of the east and west ends of the south wall (S1-2) [15]. This distribution is shown in Fig. 2.

According to the measurements taken, the east and west walls are approximately $24.82 \mathrm{~m}$ in length; the east and west sections of the north wall are roughly $21.18 \mathrm{~m}$; the east and west units of the south wall measure approximately $3.83 \mathrm{~m}$ in width; the overall height of the eave wall is roughly $5.33 \mathrm{~m}$; and the mural measures $4.76 \mathrm{~m}$

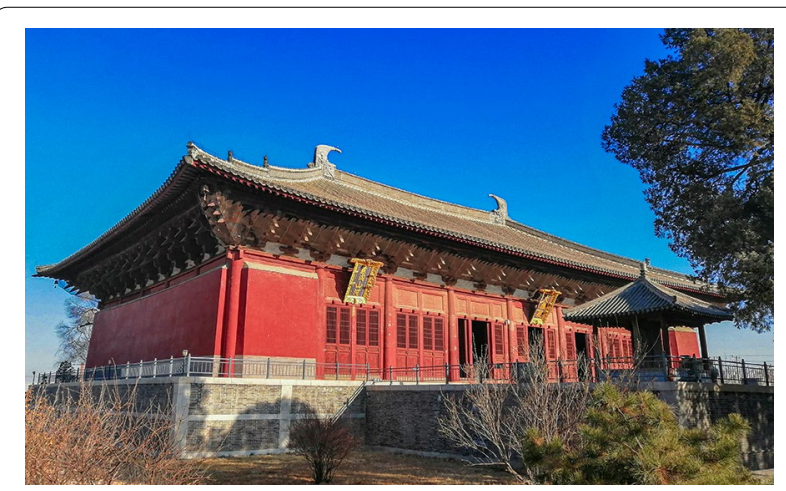

Fig. 1 Daxiong Hall in Fengguo Temple 


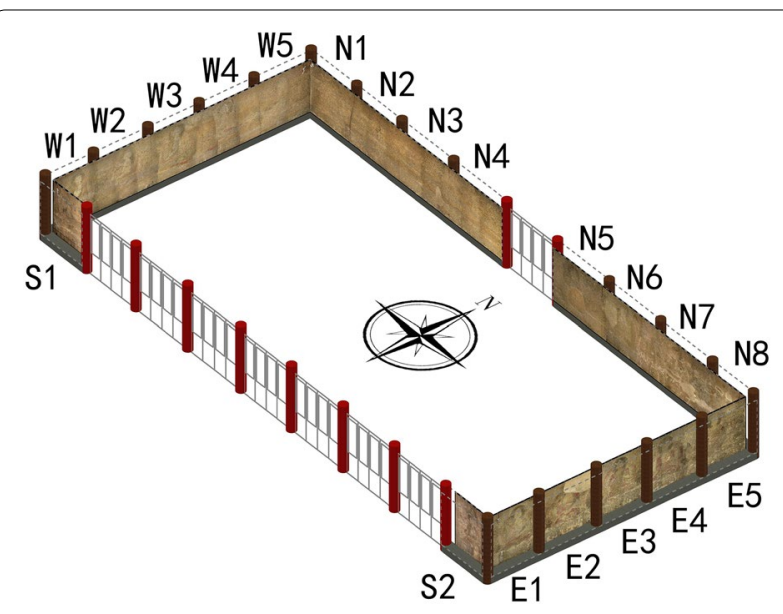

Fig. 2 The distribution of the eave wall mural

in height. The eave wall mural is thus characterized by a large size and strong integrity.

\section{The nature of the secondary cracks}

In the 1930s, the Japanese scholar, Sekino Tadashi, took a group of black-and-white photos of the eave wall mural during his exploration of Fengguo Temple [16]. After comparing them with existing murals, we found that most of the cracks visible in his photos have been filled with mud and lime plaster (Fig. 3), with only a few remaining in their original state. According to the engineering report, the largescale filling of cracks and missing parts was one of the supporting measures for the in-situ reinforcement and protection project, meaning that the majority of the existing cracks on the mural's surface were generated recently. Moreover, we can further identify the secondary cracks by observing their features and archaeological intrusion relations from a short distance. The vector diagram of the cracks' planar distribution was drawn with AutoCAD software, and the results after having deleted the original cracks can be seen in Fig. 4.

The secondary cracks on the eave wall's surface can be divided into three categories according to their nature. The first category contains the long longitudinal cracks at the eave column positions, which developed vertically and generally run through the entire wall from top to bottom, dividing the mural into units. Some developed into several segments, yet these remain independent from one another. Most of these cracks have caused the tear of added backing layers, and the adjacent walls are often dislocated due to shear failure. In terms of orientation, the cracks on the north wall are clearly more serious than those on the east and west walls. This is most noticeable in the crack at the junction of N1 and $\mathrm{N} 2$, whose widest point reaches a staggering $5 \mathrm{~cm}$. The second category includes the general cracks in the unit, which is less serious than the first category. In addition to some long transverse cracks that intersect with the longitudinal ones at the eave columns, other cracks mostly

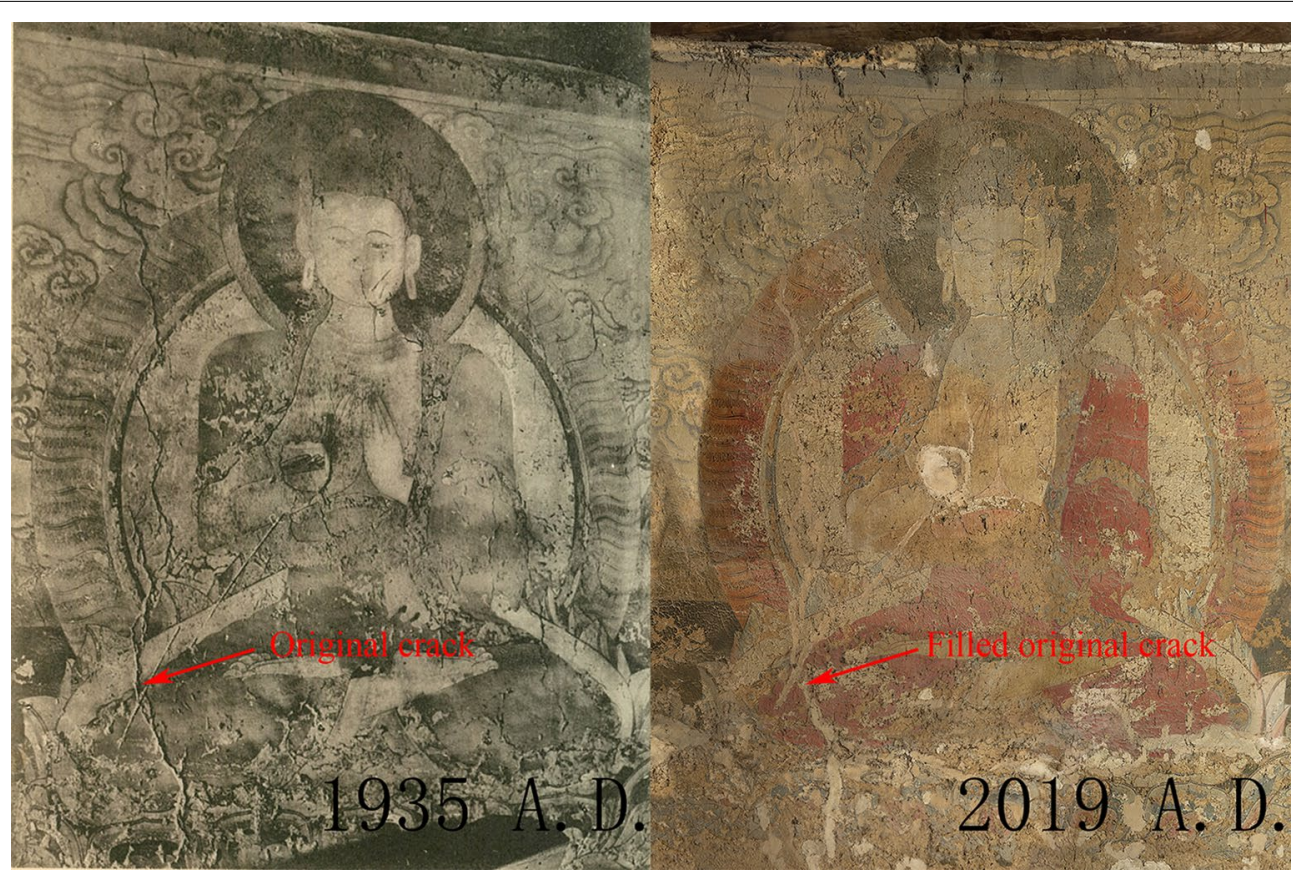

Fig. 3 A contrast between the eave wall mural's past and present (at the E4 position) 


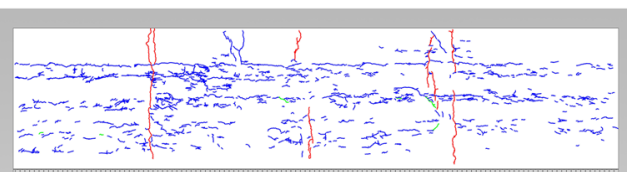

The west section of the north wall

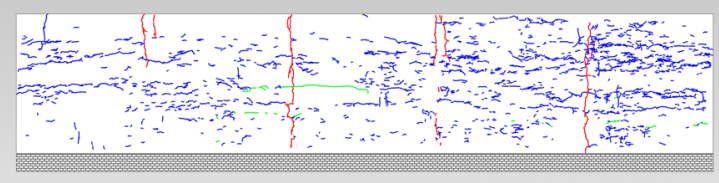

The west wall

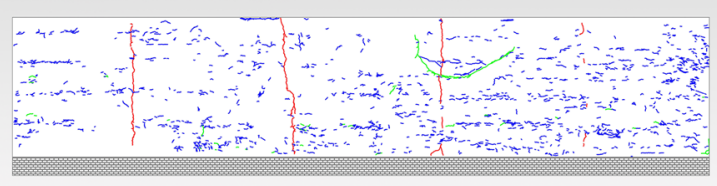

The east wall

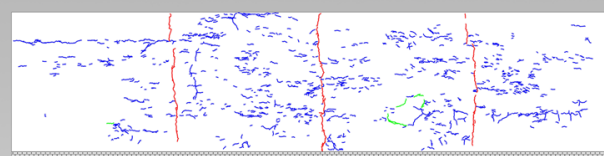

The east section of the north wall

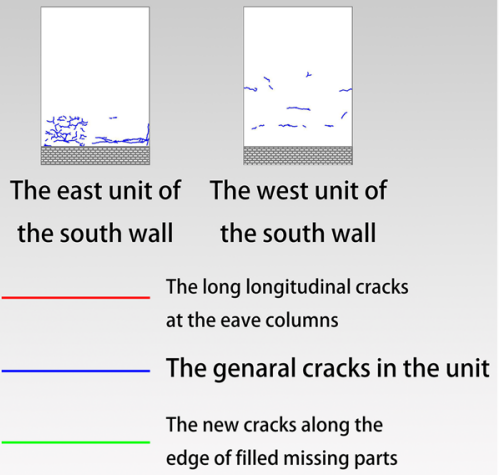

Fig. 4 Vector diagram of the secondary cracks' planar distribution

form transverse development trends in the form of short crack groups. Several rows of parallel distribution formed among different short crack groups in the same unit. There are also clear deformations near some cracks. The third category comprises the new cracks along the edge of the filled missing parts. There are few cracks within this category, and those that are developed in irregular directions, which is mainly the result of internal stress releasing along the weak edge of the filled parts.

\section{The existing structural features of the mural}

Before the reinforcement and protection in the 1980s, the eave wall was successively structured with a paint layer, a background layer, a fine mud layer with added fibrilia, a coarse mud layer with added straw, and a supporting wall made of adobe bricks. The adobe wall contained stabilityenhancing embedded columns and wooden frames [13].

An in-situ scheme was adopted for the mural' s reinforcement and protection project: the mural was temporarily supported from the front by a wooden bracket, allowing the adobe wall to be dismantled and new support structures to be added from the back. The work was systematically conducted from unit to unit, top to bottom, section by section. The thinned mud layer was initially reinforced with polyvinyl butyral and then further strengthened with two backing layers made of an epoxy resin/glass-fiber composite. The reinforced mural was integrally hoisted on an added red brick wall with $\mathrm{H}$-shaped fixtures still made of the glass-fiber reinforced plastic (GFRP) material. Finally, an adobe wall was built to encapsulate the red brick wall and eave columns were wrapped by them [13].

The filed investigation results (see Figs. 5 and 6) revealed a cavity $2-10 \mathrm{~cm}$ thick between the GFRP backing and the red brick wall, in addition to the structure mentioned in the engineering report. We can infer highly important information from this cavity regarding the mural's structure, something which has been ignored in previous investigations [12]. The red brick wall was built roughly and with little precision, and the gaps between the bricks are relatively large. Furthermore, there are 5-6 parallel rows of horizontal wood keels adhered to the GFRP backing. They are roughly $3 \mathrm{~cm}$ thick, $10 \mathrm{~cm}$ in height, and their length is approximately equal to the width of a unit. However, there is no physical connection between the wood keels and the red brick wall, and certain keels have split near the bonding surface due to the deformation of the materials. The wood keels of two adjacent units are discontinuous, and their upper and lower positions are relatively staggered. Moreover, their transverse extension does not cross the longitudinal cracks without exception. The tips of some of the wood keels are covered by the upturned fiberglass cloth of adjacent units, which is consistent with the engineering report's description that the reinforcement was conducted unit by unit. The combination of wood keels and GFRP backing was a routinely used support method for detached murals in China in the 1970s and 80s [17]. The wood keels were generally arranged into a grid frame to strengthen the level of support and enhance the mural's integrity. 


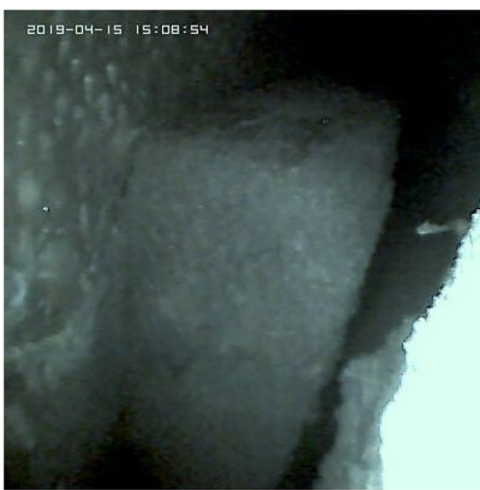

(a) The end of the wood keel

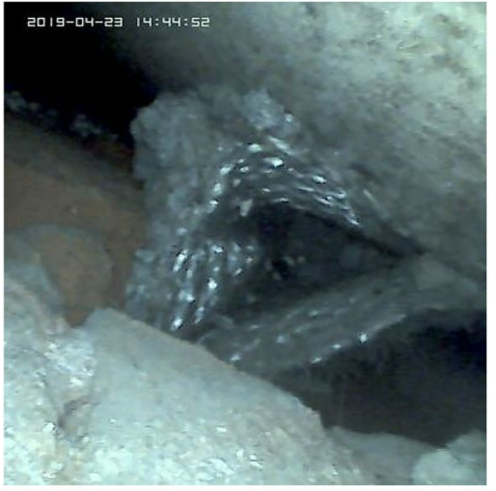

(d) The GFRP fixture

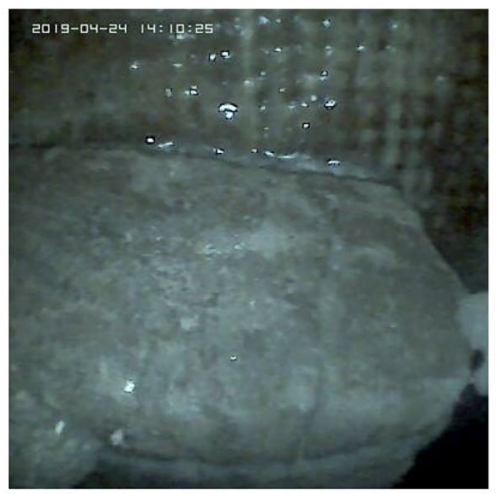

(b) The wood keel bonded to the GFRP backing

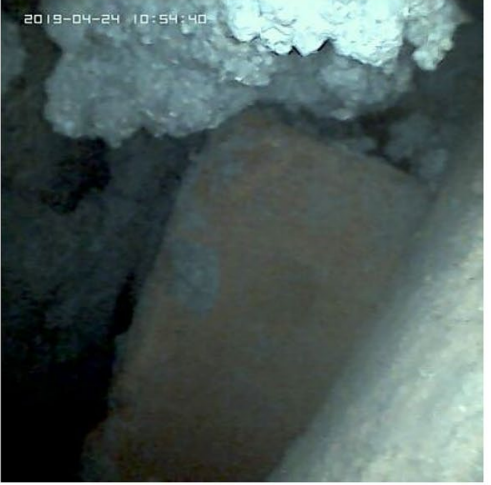

(e) The roughly built red brick wall

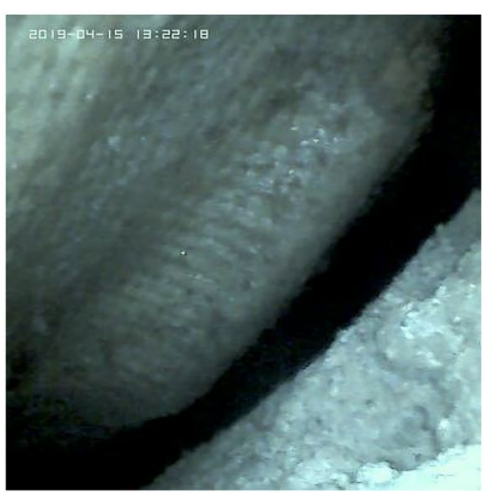

(c) The wood keel covered by the GFRP backing

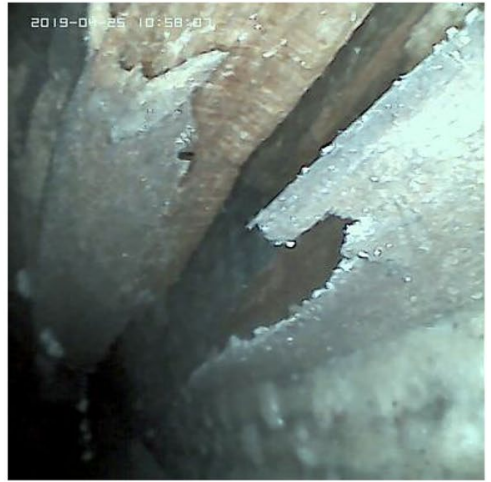

(f) Splitting of the wood keel

Fig. 5 Endoscopic photographs of the eave wall's internal structure details

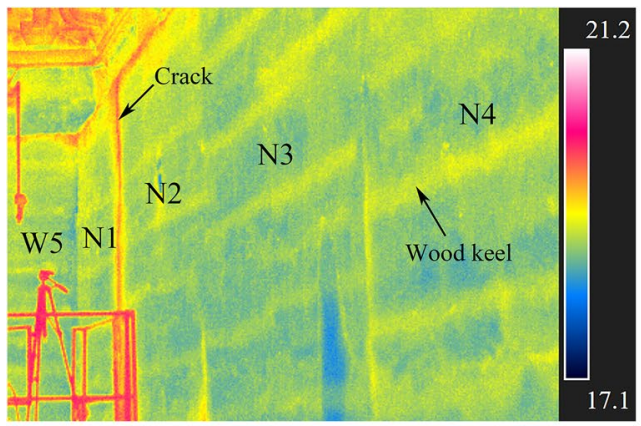

(a) The northwest corner

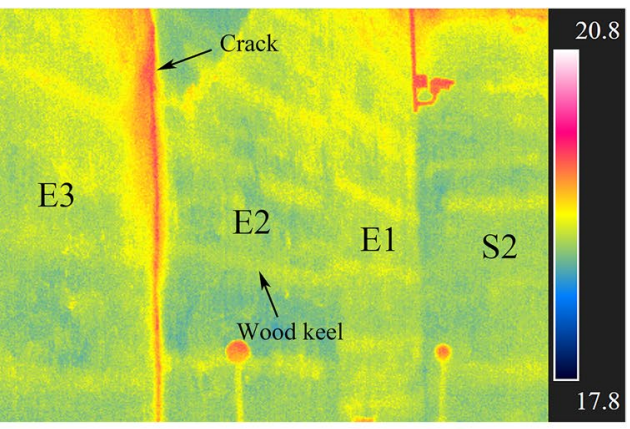

(b) The southeast corner

Fig. 6 Infrared thermal images of the wood keels' arrangement

However, due to the Daxiong mural's large size, applying the grid frame of wood keels in the in-situ reinforcement project was far from straightforward. Therefore, only horizontal wood keels were applied in the order of the top-down reinforcement, instead of vertical wood keels.
The wall structure at the junction of two adjacent units (which is the joint part of the wood keels), is somewhat different from that in the unit due to the existence of inner eave columns. In order to protect against corrosion and alleviate expansion stress, two layers of reeds and flat tiles were wrapped around the wooden column, and a 


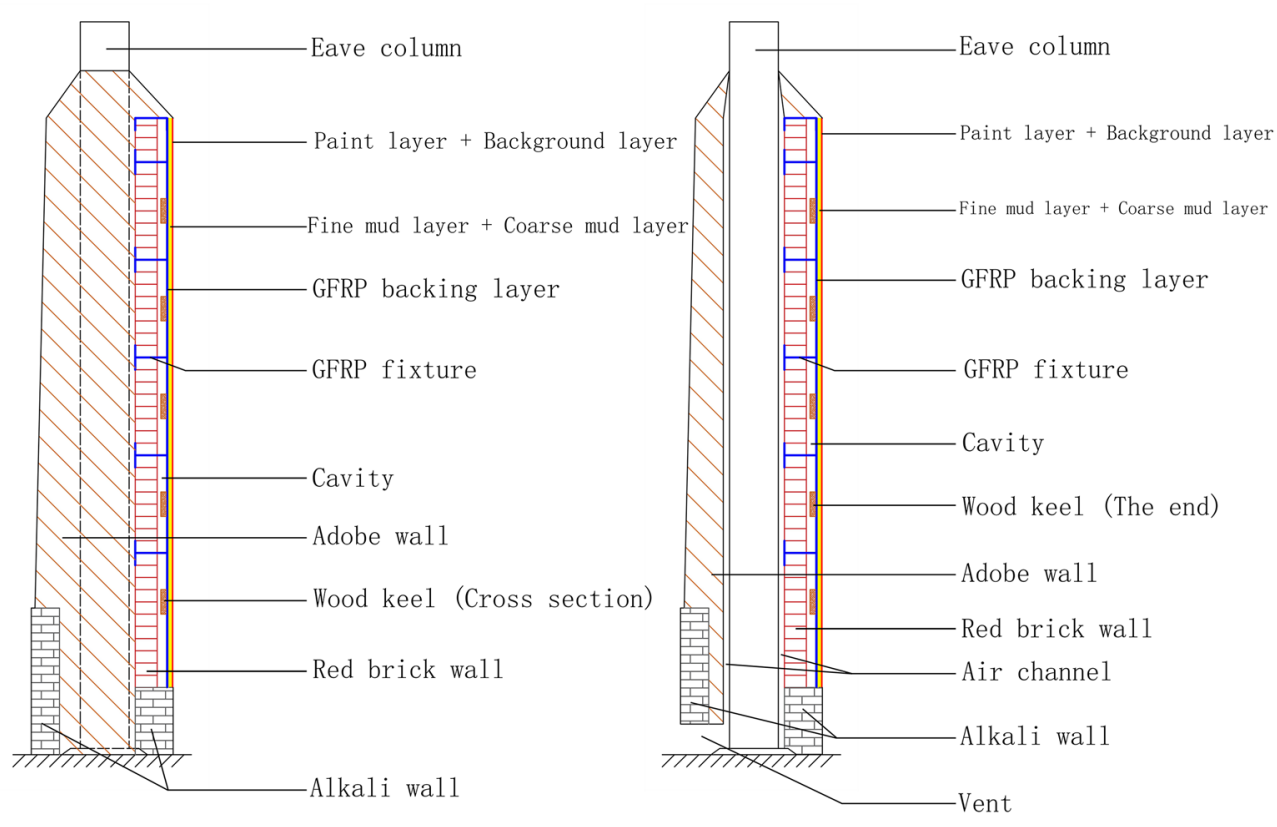

(a) Mural structure in the unit

Fig. 7 A sectional view of the existing structure of the eave wall mural

(b) Mural structure at the eave column

vent was arranged towards the column root on the external wall. The loose reeds form a $5 \mathrm{~cm}$-thick ring of air channel around the wooden column, which is connected to the cavity structure through the gaps between the red bricks. The existing basic structure of the eave wall mural is shown in Fig. 7.

\section{The environmental characteristics of the mural's location}

Yixian County is located in the valley between the Songling and Yiwulu mountains, and is only $70 \mathrm{~km}$ from the Bohai Sea. Affected by the monsoon climate and the topographic narrow pipe effect, the country receives heavy winds throughout the year, though these are strongest in spring [18]. The terrain around Fengguo Temple's main hall is open, and the outside air easily enters the wall through the vents placed at the eave columns, which has a continuous impact on the mural. It is noticed that the wind speed at the longitudinal cracks on the inner wall (the maximum can reach $1.4 \mathrm{~m} / \mathrm{s}$ ) varies with the external wind speed. The hall's north wall is close to the Daling River, with few natural or manmade barriers. This condition, combined with the air pressure difference between the direct sunlight and shaded areas, results in the north wall experience stronger winds than the rest.

Figure 8 shows the changes of near-surface atmospheric temperature and relative humidity in Yixian from 2008 to 2017. The maximum fluctuation range of atmospheric temperature during this timeframe was -27.3 to $41.3{ }^{\circ} \mathrm{C}$. Additionally, the days in which the minimum temperature fell below $0{ }^{\circ} \mathrm{C}$, and the maximum temperature exceeded $20{ }^{\circ} \mathrm{C}$ accounted for $16 \%$ and $9 \%$ of days during this timeframe, respectively. The maximum fluctuation range of the average daily humidity was $11-99 \%$, and humidity rose above $70 \%$ for approximately a third of the time. Figure 9 shows the hourly changes of air temperature and relative humidity in the main hall from May 2019 to January 2021, with the fluctuation range of -11.28 to $30.52{ }^{\circ} \mathrm{C}$ and $24.49-83.12 \%$, respectively. We should note that these ranges are slightly less volatile than the outdoor atmospheric environment.

Figure 10 shows the infrared thermal images of the north wall (N1) surface during the course of a sunny day (February 2, 2019, sunrise at 7:06 a.m. and sunset at 17:11 p.m.), which visually reflects the external environment's impact on the mural body from the perspective of heat transfer theory. The vertical line near the right edge of the image is the long longitudinal crack at the eave column, and the horizontal parallel stripes are the wood keels behind the GFRP backing. At 9:00 a.m., the mural's surface temperature was relatively uniform, and the temperature at the long longitudinal crack was slightly lower than that displayed in other parts. At 12:00 noon, the surface temperature of the mural increased as a whole, the temperature at the long longitudinal crack was significantly higher than elsewhere, and the stripes of the wood 


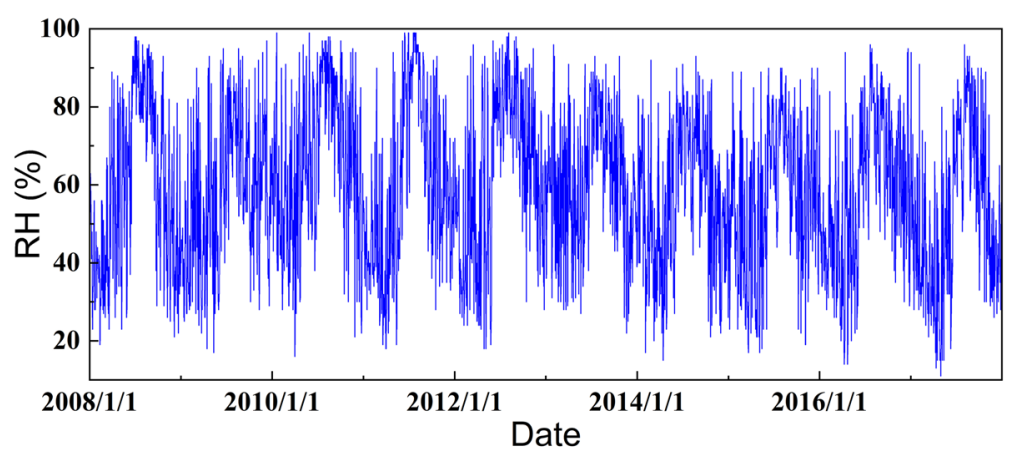

$\mathrm{RH}(\%)$

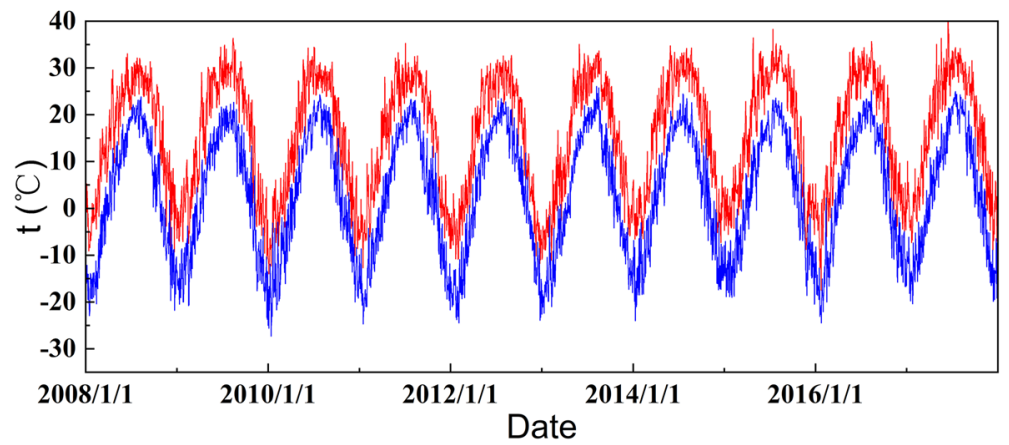

$\mathrm{t}\left({ }^{\circ} \mathrm{C}\right)(\mathrm{Max})$

$\mathrm{t}\left({ }^{\circ} \mathrm{C}\right)(\mathrm{Min})$

Fig. 8 Diurnal variation curve of the near-surface atmospheric temperature and relative humidity of Yixian County between 2008 and 2017
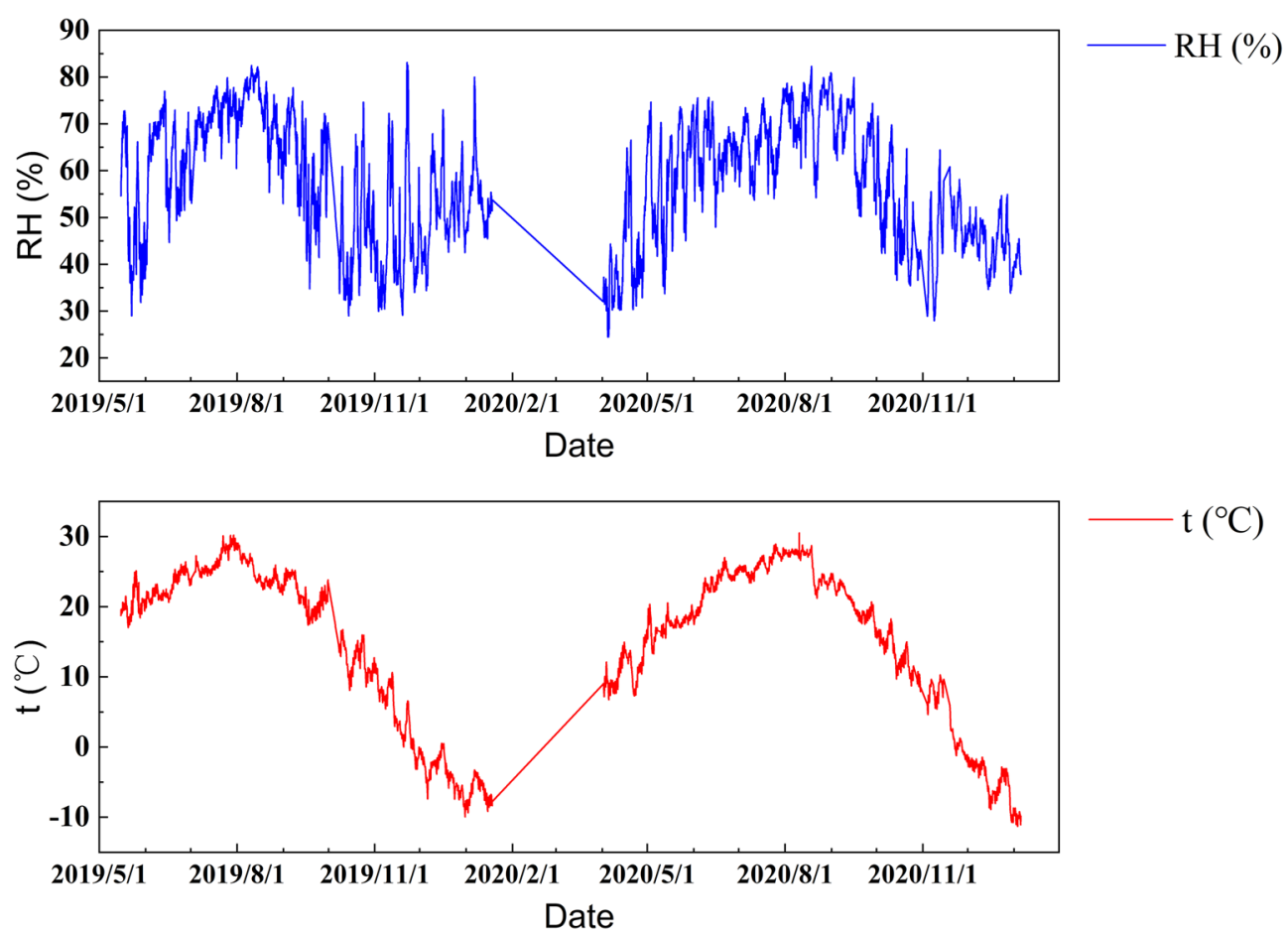

Fig. 9 Hourly change curve of the air temperature and relative humidity in Daxiong Hall from May 2019 to January 2021 (excluding the data regarding the continuous straight line) 


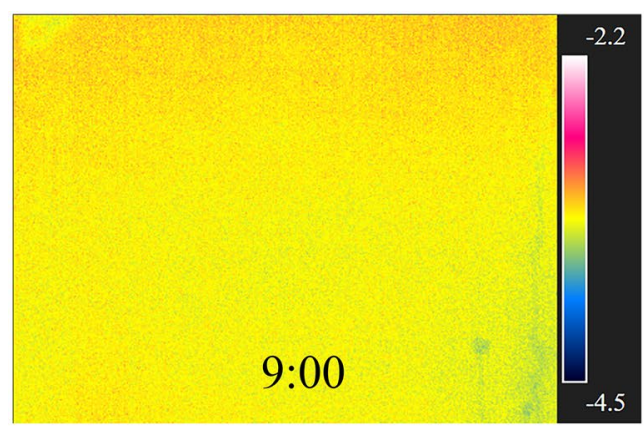

(a) 9:00 a.m.

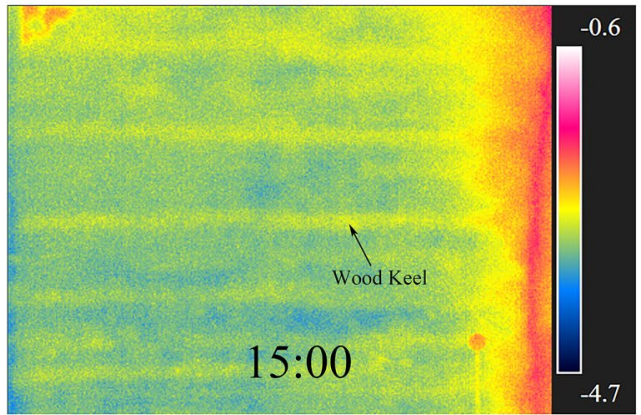

(c) 15:00 p.m.

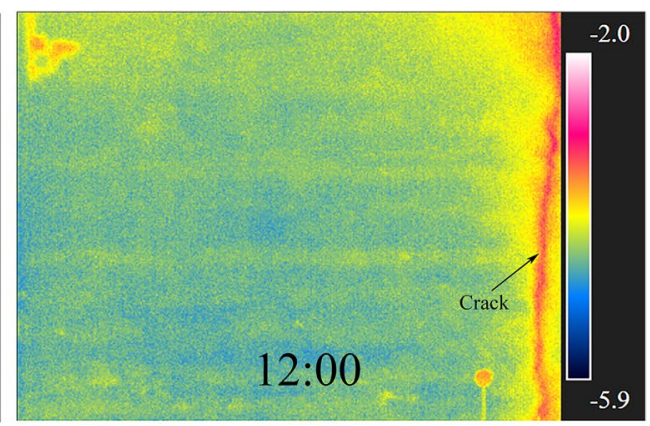

(b) 12:00 noon

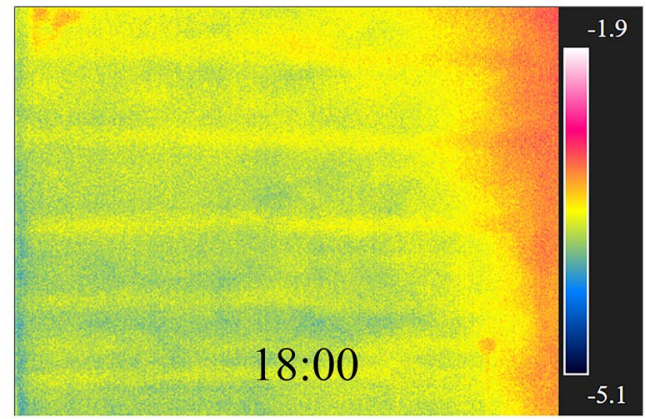

(d) 18:00 p.m.

Fig. 10 Infrared thermal images on the north wall's surface at different times during a sunny day (February 2, 2019)

keels initially emerged. At 15:00 p.m., the mural's surface temperature further increased, and a high-temperature divergence zone centered on the long longitudinal crack began to form. Moreover, the stripes of the wood keels became clearly visible. At 18:00 p.m., the surface temperature of the mural fell as a whole. The center of the high-temperature divergence zone-namely the long longitudinal crack-became less obvious due to the disappearance of the external heat source (sunset), and the stripes of the wood keels also began to fade.

\section{The deformation of the mural's surface}

The 3D scanning point cloud data of the north wall (N1-2) at 11:00 a.m. on December 2, 2018, and the west wall (W4-5) at 14:00 p.m. on December 2, 2018, were respectively packed into a grid model as a reference, and the other three 3D scanning point cloud data of the corresponding walls from December 2018 to April 2019 were compared with it (the deviation chromatogram was made as shown in Fig. 11). The different tonalities and color temperatures in the figure represent the direction and degree of deformation. We can see that the eave wall mural's surface deformation can be characterized by both integrity and locality. Among them, the deformation of the area near the longitudinal and transverse long cracks differs from the adjacent area, while the deformation of the transverse short cracks groups in the unit are not immediately obvious. There are stripe areas parallel to each other in the unit, which seems to be consistent with the position of the horizontal wood keels. The deformation degree in the stripe areas is clearly smaller than in other areas, which could well be explained by the restriction of the horizontal wood keels and the GFRP fixture. The figure also depicts that the deformation phenomenon of block areas is by no means consistent, which can be interpreted as the non-uniform deformation restriction conditions inside the eave wall .

Generally speaking, the surface deformation of the mural in the two stages before and after January 2019 has a reverse trend, which corresponds to the changing atmospheric temperature (which first decreases, then rises) during this period, indicating that the deformation may be a cyclical process tied to temperature fluctuations. In addition to the chromatograms, this was also reflected in the 3D deviation values (see Table 2). Among them, the maximum deviations were all above $100 \mathrm{~mm}$, which could be explained by cobwebs and hanging floccule in some positions on the surface of the mural being disturbed and displaced by external forces (a both random and accidental phenomenon). We cannot exclude the possibility that some other large deviation values are the result of this situation. The mean deviation values of the north and west walls are small, and both 


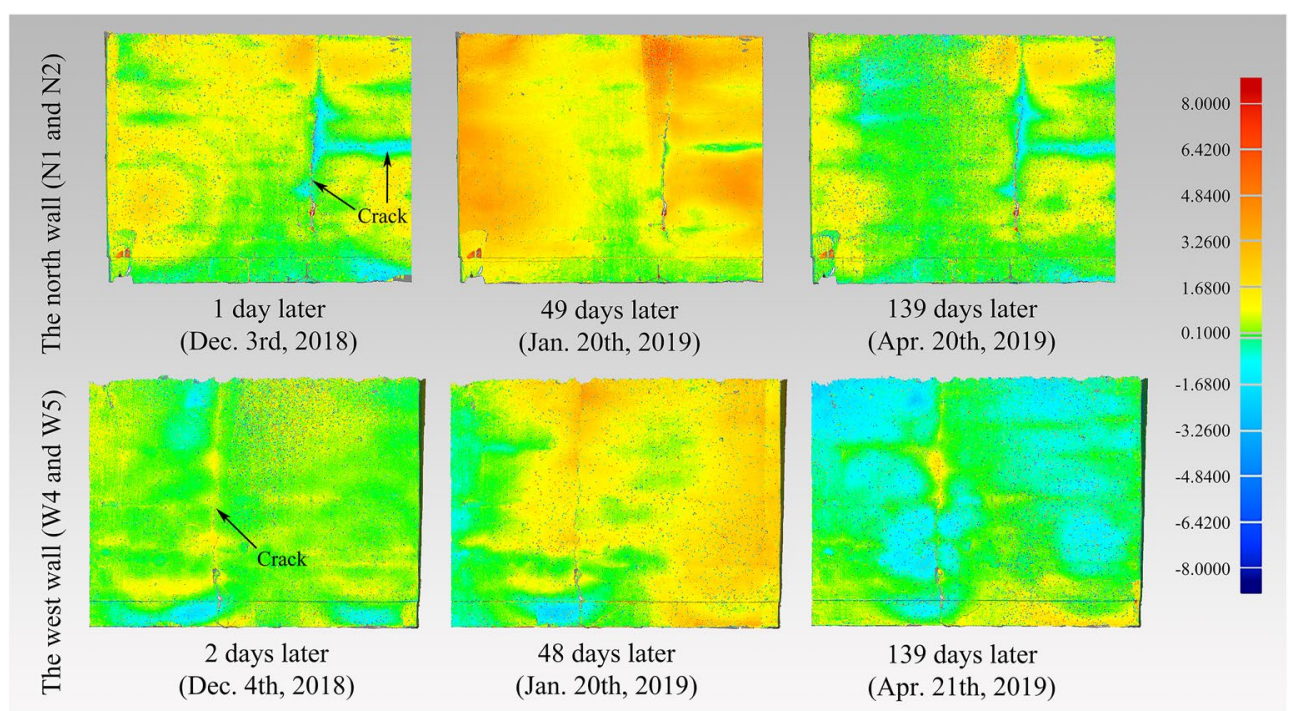

Fig. 11 Deviation chromatogram of the eave wall mural's surface deformation

rise before falling, indicating that small absolute deviation values may be related to the deformation caused by temperature changes. The standard deviation in the table is the error of mean squares calculated from the absolute deviation, and represents the dispersion of the absolute deviation values. We can see that the standard deviation of the north and west walls increases before remaining essentially unchanged. Combined with the change of the mean deviation, this could be due to the differentiation of the absolute deviation values in the second stage, which is to say that the smaller absolute deviation decreased while the larger absolute deviation further increased. The former corresponds to the cyclical process of the thermal stress deformation, while the latter seems congruous with the entropy increase process of the random displacement.

\section{Analysis and discussion \\ Relations between structural defects and the nature of secondary cracks}

The results revealed strong correlations between the mural's existing structure and the nature of secondary cracks, which are realized through the wall deformation and stress distribution. Like other ancient wooden architecture structures in China, the eave wall of Daxiong Hall is non-bearing. Moreover, the hall's foundation is solid without uneven settlement. Consequently, the stress causing the cracks comes not from the outside, but from the wall itself. Since the red brick and adobe walls are intact, the stress is likely generated in the GFRP backing and its outer layers. Previous research has shown that the epoxy resins used to make the GFRP backing undergo significant curing shrinkage and environmental deformations during the shaping and keeping stages, respectively [19]. The material's flexibility and bending strength worsens with aging. In terms of the uneven distribution of restriction intensity, deformation generates stress at the edge of the region where the restriction intensity is greatly different. When the stress exceeds the mechanical limit of the material itself, brittle fracture occurs in the material, leading to cracks. The GFRP material is anisotropic in mechanical strength, and this mechanical strength is greater along the fiber direction than perpendicular to it [20]. This determines that the release of stress preferentially causes shear failure in the direction of thickness, so that both sides of the crack appear to be anterior and posterior dislocations, and the existence of the cavity structure provides the necessary spatial conditions for the deformation and stress release.

The position of the eave column, as the junction of two adjacent units, lacks the overall reinforcing effect of transverse wood keels, making it relatively weak in structure. As the murals of adjacent units were respectively strengthened, the different installation conditions (e.g., position and tightness) of fixtures and wood keels caused differences in restriction strength between units, thus generating the overall stress. The concentration and superposition of stress, and structural weaknesses, are the two potential internal causes of the formation of long longitudinal cracks. The cracks in the units, and the wood keels behind the GFRP backing, have similar parallel distributions of multiple rows. After further comparison, we found that the transverse cracks mostly developed near the edge of the transverse wood keels, that is, the stress was confined to the horizontal direction and released in a concentrated way. This seems 
Table 2 3D deviation values of the mural surface deformation

\begin{tabular}{|c|c|c|c|c|}
\hline \multirow[t]{2}{*}{ Wall } & \multirow[t]{2}{*}{ Time } & \multicolumn{3}{|l|}{ 3D deviation (mm) } \\
\hline & & $\begin{array}{l}\text { Maximum deviation } \\
(+/-)\end{array}$ & $\begin{array}{l}\text { Mean deviation } \\
(+/-)\end{array}$ & $\begin{array}{l}\text { Standard } \\
\text { deviation }\end{array}$ \\
\hline \multirow[t]{3}{*}{ The north wall (N1 and N2) } & $\begin{array}{l}1 \text { day later } \\
\text { (Dec. 3rd, 2018) }\end{array}$ & $156.8053 /-201.2671$ & $1.0539 /-1.4805$ & 4.3378 \\
\hline & $\begin{array}{l}49 \text { days later } \\
\text { (Jan. 20th, 2019) }\end{array}$ & $264.2090 /-275.8067$ & $2.0303 /-2.0625$ & 6.5675 \\
\hline & $\begin{array}{l}139 \text { days later } \\
\text { (Apr. 20th, 2019) }\end{array}$ & $238.5293 /-263.7701$ & $1.2916 /-1.8002$ & 6.7424 \\
\hline \multirow[t]{3}{*}{ The west wall (W4 and W5) } & $\begin{array}{l}2 \text { days later } \\
\text { (Dec. 4th, 2018) }\end{array}$ & $207.0374 /-161.5413$ & $0.9012 /-1.0418$ & 3.2814 \\
\hline & $\begin{array}{l}48 \text { days later } \\
\text { (Jan. 20th, 2019) }\end{array}$ & $300.6210 /-136.2238$ & $2.0603 /-3.7366$ & 7.6747 \\
\hline & $\begin{array}{l}139 \text { days later } \\
\text { (Apr. } 21 \text { st, 2019) }\end{array}$ & $202.6118 /-199.6987$ & $1.8080 /-1.2639$ & 7.0865 \\
\hline
\end{tabular}

to suggest that the transverse wood keels only play a unidirectional reinforcing role. Since there is no physical connection between the wood keels and the red brick wall behind them, the keels may move in line with the deformation or displacement of the GFRP backing, thus offsetting part of the overall stress, making the local stress at the edge of the reinforced parts by wood keels play a decisive role in cracks generating. Therefore, the transverse cracks in the units are generally less serious than the longitudinal cracks at the eave columns.

\section{The impact of environmental factors on the mural body}

The climate in Yixian County is characterized by cold and desiccated winters, torrid or wet summers, and rapid changes (and annual fluctuations) of temperature and humidity in the spring and autumn. Although the main hall helps cushion against the external environment, the effect is very limited. The good air fluidity further strengthens temperature and humidity's influence upon the mural. When the epoxy GFRP backing material is aged in a humid and hot environment, the crosslinking structure of the resin matrix is destroyed, leading to the failure of the interface bonding of the "matrix-fiber" [21]. This in turn leads to thermal stress damage, resulting in a significant decrease in the mechanical properties of the material. At the same time, temperature and humidity fluctuations generate moist and hot expansion stress and steam pressure in the epoxy GFRP backing and mud layer, thereby causing the materials to disfigure and crack, and the connection between layers to fail.

There are clear and observable correlations between the variation of infrared thermal images of the mural's surface and the diurnal variation of atmospheric temperature on sunny days. Firstly, compared with other parts, the temperature changes at the long longitudinal cracks are more responsive to the diurnal variation of atmospheric temperature, which proves that the long longitudinal cracks are well-connected to the outside atmosphere, and the heated or cooled outside air can penetrate to the crack sites through the vents and air channels, causing lasting damage to the mural. Secondly, with the passage of time, a hightemperature divergence zone centered on the long longitudinal cracks gradually formed. Simply put, the mural body and wood keels located close to the eave columns would also significantly increase in heat with the long longitudinal cracks. This is partly the result of heat conduction via solid materials and partly the direct influence of outside air, which enters through the cavity between the GFRP backing and the red brick wall. Due to the temperature fluctuation in the divergence zone being far more dramatic than in other parts, the long transverse cracks (the most serious among the second category of secondary cracks) only appear near the eave columns and cross with the long longitudinal cracks. Moreover, the wood keel stripes gradually appeared only after noon, and began to fade away after sunset. This change seems to be synchronous on each part of the stripes, which suggests that the influence of the external environment on the mural is realized not only through the air channel at the eave column, but also the heat conduction via the eave wall. The influence of this heat conduction pathway is both milder and slower than it should be due to the effective buffering of the $1.2 \mathrm{~m}$-thick eave wall.

\section{Causes and treatments of secondary cracks}

Based on the above discussion, we can summarize two major models of the ways in which the external environment enhances the formation of secondary 


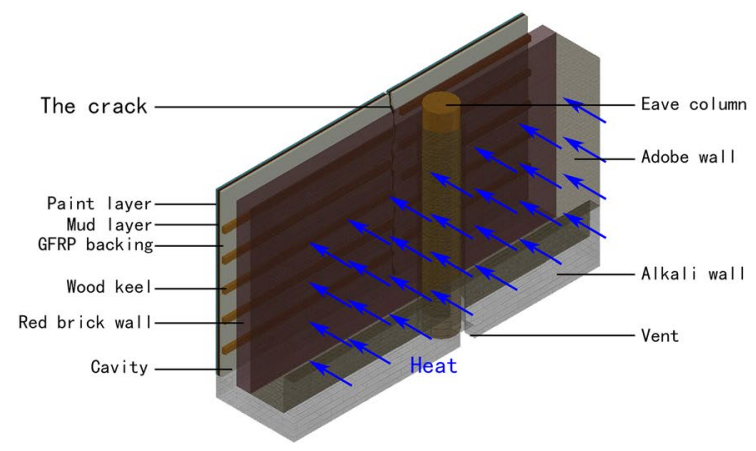

(a)The pathway of heat conduction

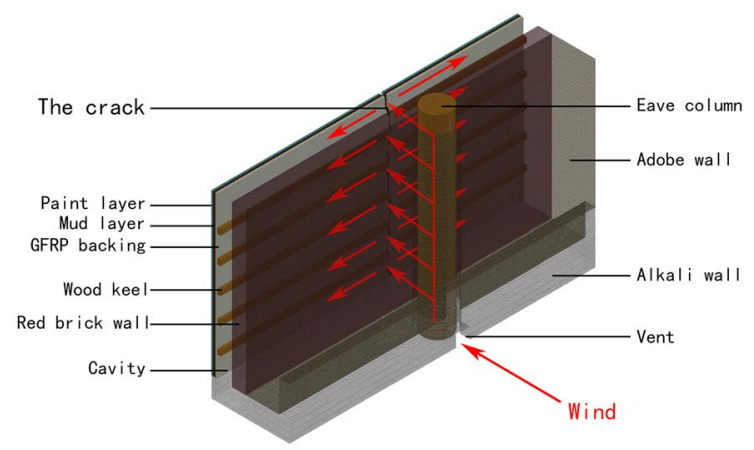

(b) The pathway of air channel

Fig. 12 The pathway of the external environment acting upon the mural body

cracks on the eave wall mural through its structural defects (Fig. 12):

(1) The effects of the atmospheric temperature and relative humidity levels-as well as their dramatic fluctuations-can penetrate to the GFRP backing layer through the air channel at the eave column with the help of good air fluidity. This results in the GFRP deteriorating and deformation, making the stress release directionally along the end and edge of the wood keel under its restriction, thereby generating transverse and longitudinal long cracks near the eave column.

(2) The external environment takes the eave wall as the medium to exchange heat with the mural body, generating both overall temperature stress inside the unit as well as local temperature stress at the edge of the wood keel. The former further promotes the shear failure at the eave column position, while the latter induces the formation of the parallel short crack groups between the horizontal wood keels.

The results clearly show that the deep influence of external environment and the non-uniformity of material reinforcement are the two major causes of the secondary cracks. Consequently, we can strongly recommend that these factors should be protected against in subsequent protective or restorative measures. Air channels should either be blocked or changed, and an insulation layer should be added to reduce the impact of the external environment on the mural body. Moreover, the backing and supporting materials should be removed in favor of those which have smaller rates of expansion and contraction. Lastly, the connection between layers should be strengthened to offset the stress caused by differing restriction conditions.

\section{Conclusions}

This paper has investigated the causes of a secondary disease of an architectural mural preserved in-situ. Through the comprehensive investigation and analysis of the mural's location and distribution, the disease features, the eave wall's structural defects, the environmental characteristics, and the deformation dynamic conditions, we can draw the following conclusions:

(1) Most of the existing cracks on Daxiong Hall's eave wall mural are secondary cracks, which are related to the changes of the eave wall's structure after the in-situ reinforcement and protection project in the 1980s.

(2) The secondary cracks are the result of environmental stress, and were caused by the directionally released stress along the weak parts due to the temperature- and humidity-related deteriorating and deformation of the GFRP.

(3) The external environment contributes to the formation of the secondary cracks in two ways: air channels at the eave columns and heat conduction via the eave wall. The influence of the former is more intense and critical than that of the latter.

(4) To restore the mural's stability, the deep influence of the external environment should be reduced, and the mural's structure strengthened. This can be done by blocking or changing the air channel, or by replacing the backing and supporting materials with ones more resilient to the weather. 


\section{Abbreviations}

LAN: Local area network; 3D: Three-dimensional; GFRP: Glass fiber reinforced plastic.

\section{Acknowledgements}

Thanks to Ms. Ying Ren and her friends for providing endoscopic equipment. Thanks also to Mr. Fengsheng Huang and Mr. Lun Yue for taking the mural photographs. Our sincere gratitude to Mr. Kaoru Suemori of the National Museum of Ethnology in Japan for providing historical photographs of Fengguo Temple's murals. We would also like to express our thanks to Mr. Hui Wang and Mr. Haoyuan Zheng for providing 3D laser scanning technical support. Thanks to Dr. Qingpeng Cao and Dr. Xiaobo Liang of Zhejiang University for providing online environmental monitoring system. Thanks also to Mr. Edward from CAMBRIDGE Proofreading \& EDITING LLC for proofreading the English of this paper. Last, but by no means least, we sincerely thank Mr. Haiying Kang and Mr. Jian Liu of Fengguo Temple Management Office in Yixian County for their assistance in the field investigation.

\section{Authors' contributions}

CL presided over the entire research piece and designed the manuscript's overall framework. YH conducted the field investigation and data analysis, and was a major contributor to the writing of the manuscript. QL systematically analyzed the micro causes of the secondary crack disease. FW collected and organized relevant historical documents. All authors read and approved the final manuscript.

\section{Authors' information}

$\mathrm{CL}$ is an associate professor at the School of Cultural Heritage, Northwest University. His main research direction is the conservation of murals and bronzeware.

$\mathrm{YH}$ is a graduate student majoring in cultural heritage conservation at the School of Cultural Heritage, Northwest University. His main research direction is the conservation of murals and bronzeware.

QL graduated from the School of Cultural Heritage, Northwest University with a master's degree in cultural heritage conservation. She is now working in the Department of Conservation and Restoration of Shaanxi History Museum. FW is the director of Yixian County Administration for Cultural Heritage.

\section{Funding}

This research forms part of the "Protection, Research and Design Project of the Mural in Daxiong Hall of Fengguo Temple" approved by the State Administration of Cultural Heritage of China, and supported by the special subsidy fund for the protection of key national cultural relics.

\section{Availability of data and materials}

More photographs of the mural (including the appearance photographs, endoscopic photographs, and infrared thermal images) taken during the current study are available from the corresponding author upon reasonable request. The datasets of the $3 \mathrm{D}$ scanning point cloud, and the temperature and humidity in Daxiong Hall are not publicly available due to their use in other unpublished studies. However, they are available from the corresponding author upon reasonable request. The near-surface atmospheric temperature and humidity in Yixian County datasets analyzed during the current study are available in the repository of Resources and Environmental Science and Data Center of the Chinese Academy of Sciences, https://www.resdc.cn/data. aspx?DATAID $=230$.

\section{Declarations}

\section{Competing interests}

The authors declare that they have no competing interests.

\section{Author details}

${ }^{1}$ School of Cultural Heritage, Northwest University, Xi'an, China. ${ }^{2}$ Shaanxi History Museum, Xi'an, China. ${ }^{3}$ Yixian County Administration for Cultural Heritage, Jinzhou, China.

Received: 1 June 2021 Accepted: 17 September 2021

Published online: 11 October 2021

\section{References}

1. Du JG, Guo SX, Chen P, Guo QL, Chen JY, Yu SJ. Experimental study of crack initiation in wall-paintings of Mogao Grottoes. Rock and Soil Mechanics. 2017;38(1):19-25.

2. Wang YL. Investigation on the preservation of temple murals in western Inner Mongolia. World Antiq. 2020;5:45-7.

3. Wood RL, Hutchinson TC, Wittich CE, Kuester F. Characterizing cracks in the frescoes of Sala degli Elementi within Florence's Palazzo Vecchio. In: loannides M, Fritsch D, Leissner J, Davies R, Remondino F, Caffo R, editors. Progress in Cultural Heritage Preservation. EuroMed 2012. Lecture Notes in Computer Science, vol 7616. Springer, Berlin, Heidelberg.

4. Zhang LZ, Yuan SL. Investigation and protection of murals in Tianfu Hall of Dai Temple in Mount Tai. China Cult Herit Sci Res. 2009;3:67-71.

5. HeX. Mechanisms of secondary diseases of polychrome cultural heritages and failure of typical conservation materials. PhD thesis. Hangzhou: Zhejiang University; 2019.

6. Li JM, Zhang H, Fan ZX, He X, He SM, Sun MY, et al. Investigation of the renewed diseases on murals at Mogao Grottoes. Heritage Science. 2013;1:31.

7. Cheng Q, Zhao DD, Guo H. Influences of degraded conservation polymer materials on wall paintings. Sci Conserv Archaeol. 2013;25(2):77-82.

8. Jia CS, Zhang BJ. Removing reinforcement materials from the ancient murals surface by gels: a simulation study. Sci Conserv Archaeol. 2016:28(4):9-18.

9. Zhao DD, Cheng Q, Guo H. Application of nano-emulsion in the removal of invalid cultural relic protection materials-taking fresco cleaning as an example. China Cult Herit. 2020;4:83-8.

10. Lei ZK, Zhang Y, Wan LY. Forensics, diagnosis, and evidence base: exploration of the building pathology of the Town God's Temple murals in sTong-vkhor, Qinghai, under the influence of environmental climate. South Archit. 2020;5:70-7.

11. Wan LY. Study on the deterioration mechanism for historical buildings under the moist and arid climate: taking the environment of ancient mural for example. MA thesis. Wuhan: Huazhong University of Science and Technology; 2018.

12. Liu C, Suemori K, Li Q, He Y, Wang F, Kang HY. Deterioration caused by a new support layer bonded with epoxy adhesive to the mural paintings at Fengguo Temple in Yixian, Liaoning, China. Stud Conserv. 2020;65(sup1):187-91.

13. Liaoning Cultural Heritage Protection Center, Yixian county administration for cultural heritage. Fengguo temple in Yixian County, vol. 1. Beijing: Cultural Relics Press; 2011.

14. Institute of Geographic Sciences and Natural Resources Research, CAS: Resource and environment science and data center. https://www.resdc.cn/ data.aspx?DATAID=230. Accessed 15 Nov 2020

15. Zhang XD. Buddha murals of Yuan and Ming dynasties preserved in Daxiong Hall of Fengguo Temple. Res China Front Archaeol. 2010;1:229-37.

16. Sekino T, Takeshima T. Architectures and their Buddha Statues in the Liao and Jin Period of China: atlas volume one. Tokyo: Tokyo Institute of Oriental Culture College; 1934

17. Yang WZ, Guo H, Ge QY. Study of techniques for removal of incapable artificial layer of wall painting fragments. Relics and Museology. 2009;6:184-90.

18. Yang GJ, Yan ZY. Strong wind climate characteristics and circulation analysis in Jinzhou. J Anhui Agric Sci. 2010;38(23):12347-9.

19. Li Q. Analysis on the causes of cracks disease on mural paintings of the Yuan dynasty in Fengguo Temple. MA thesis. Xi'an: Northwest University; 2019.

20. Zhang S, Yao N, Wu JP, Zhang GT. Mechanical properties of glass fiber reinforced epoxy resin composite material. Electr Eng Mater. 2016;1:11-4.

21. Gao K, Shi HQ, Sun BG, Wang ZH, Yang ZY, Xing YJ, et al. Effects of hydrothermal aging on properties of glass fiber/epoxy composites. Acta Materiae Compositae Sinica. 2016;33(6):1147-52.

\section{Publisher's Note}

Springer Nature remains neutral with regard to jurisdictional claims in published maps and institutional affiliations. 